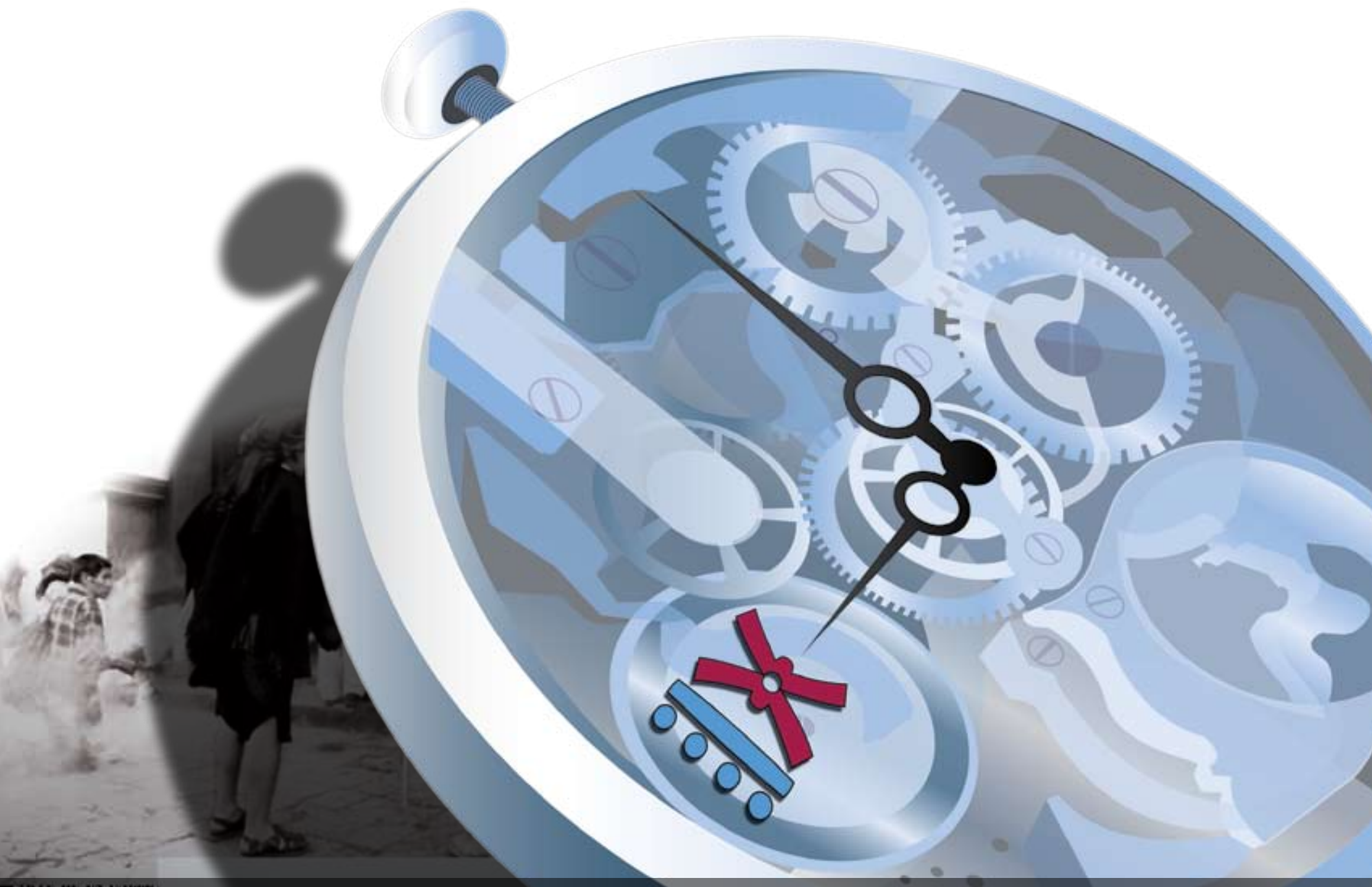

$9^{\circ}$ CONGRESO 2. CENTROAMERICANO DE H ISTO R I A
Universidad de Costa Rica

ISSN 1409-469X

Fecha de recepción: 15 de mayo 2008 Fecha de aceptación: 30 de mayo 2008

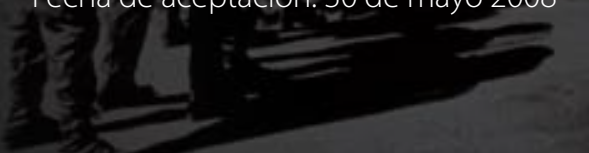

La enseñanza de la historia prehispánica en México. Análisis del libro de texto oficial y gratuito de historia de primaria

Miembros del Consejo Editorial:

Dr. Ronny Viales, Dr. Juan José Marín

Editores Técnicos:

Allan Fonseca, Andrés Cruz, Gabriela Soto

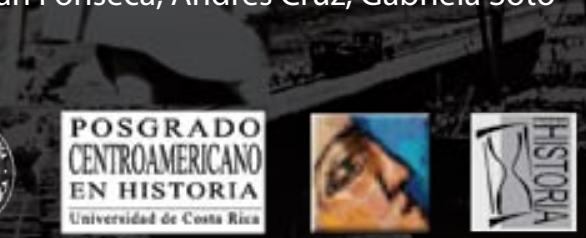


Indexaciones: Repositorio de Revistas UCR, DIALNET, Latindex, REDALYC Directorio y recolector de recursos digitales del Ministerio de Cultura de España, Directory of Open Access Journals. Diálogos Revista Electrónica de Historia ISSN 1409-469X. Número especial 2008. Dirección web: http://historia.fcs.ucr.ac.cr/dialogos.htm

\section{La enseñanza de la historia prehispánica en México. Análisis del libro de texto oficial y gratuito de historia de primaria}

Rebeca Panameño Hidalgo

Arqueóloga. Estudiante del Doctorado en Historia de la Facultad de Filosofía y Letras de la UNAM. rpanam2000qyahoo.com.mx 
La enseñanza de la historia en el nivel primaria en México $^{1}$ no ha producido buenos resultados. Como consecuencia, constantemente se escuchan opiniones de investigadores y maestros que manifiestan su preocupación por el escaso conocimiento histórico que posee, en su mayoría, la población mexicana. Se ha tratado de ubicar, en los diferentes aspectos que involucra la enseñanza de la historia, las causas de este "fracaso" educativo; por un lado, se le imputa al magisterio su deficiente preparación, y por otro, se propone la enseñanza de una historia que no se enfoque a la memorización de hechos sino que se dedique a "formar" mexicanos con una conciencia histórica, es decir, individuos que puedan comprender los procesos de transformación de las sociedades y que desarrollen la capacidad de aplicar esos conocimientos para entender su realidad e incidir en ella de manera conciente, pero no es frecuente asociar la estructura del libro de texto al fracaso educativo.

El fracaso de los estudiantes mexicanos en el aprendizaje de la historia se debe entre otros factores, a que la enseñanza de la historia está enfocada básicamente a desarrollar un aprendizaje memorístico en lugar de promover la capacidad de análisis. Este problema se debe al contenido y a la forma de enseñanza, en este caso de la historia, aspecto que no ha sido suficientemente examinado.

Por ésta razón en este trabajo se hace un análisis del contenido y de la forma en que se estructura el discurso de la historia prehispánica en el libro de texto oficial de primaria, para poder establecer, por un lado, la congruencia de este texto con la historia prehispánica producida por la Arqueología, y por otro, se propone que una de las causas del fracaso educativo es la forma en que se estructura el texto de historia prehispánica.

La Secretaría de Educación Pública (SEP) de 1984 al 88 y la revista Nexos en 1990, llevaron a cabo — cada uno por su cuenta — una evaluación del sistema educativo mexicano en el nivel primaria y llegaron a la misma conclusión: a pesar de los enormes esfuerzos del Estado por elevar la calidad educativa, ésta se encontraba por debajo de la calificación mínima aprobatoria, a México se le podía calificar como un país de reprobados². Tomando como guía los resultados de esta evaluación, en 1992, el gobierno propuso una Reforma con el fin de corregir las deficiencias de un modelo educativo que se había mantenido vigente durante 20 años.

Los nuevos programas reestablecieron la enseñanza de la historia como asignatura independiente, ya que desde 1972, la historia estuvo programada junto con Geografía y Civismo, en la materia de Ciencias Sociales. Para los creadores de la reforma, ésta fue la causa

$1 \quad$ En México, en 1959 el estado lleva a cabo una reforma educativa que implanta la obligatoriedad y gratuidad de los textos escolares para la primaria. Lo que obliga a las escuelas particulares a utilizar los mismos textos que las escuelas públicas.

2 Guevara Niebla, Gilberto, “México: ¿un país de reprobados?”, en Nexos, núm. 162, junio, México 1991. 
del bajo rendimiento escolar en esta área. Para subsanar el problema, la SEP rediseñó los planes y programas de estudio para la materia y elaboró los nuevos libros de texto. A pesar de esta reforma, el panorama de la educación en México no ha mejorado, evaluaciones recientes ${ }^{3}$ colocaron a México en el último lugar de la lista de los 30 países que conforman la OCDE ${ }^{4}$

Una de las razones de que persista esta situación, a pesar de los esfuerzos del gobierno por remediarla, es la confusión que existe con respecto a lo que es la calidad educativa, que se asocia mayormente con la provisión de infraestructura y no con los contenidos y las formas de enseñanza ${ }^{5}$. En la mayoría de los casos, las propuestas para mejorar el aprendizaje solo insisten en la necesidad de elevar el nivel de los maestros y emplear mejores técnicas didácticas. Respecto a la enseñanza de la historia, después de la reforma de 1992, que implicó un cambio en los programas y contenidos de la educación primaria y secundaria, no se ha llevado a cabo una revisión estructural del texto de historia, por tanto, el contenido y la forma no han variado a pesar del evidente fracaso. Las pocas menciones al contenido de los libros, hacen referencia a lo extenso del programa, pero no se plantea la necesidad de reestructurar la forma como se ha escrito la historia ${ }^{6}$

Al observar el contenido del programa de historia para la primaria, es evidente su extensión —el programa abarca desde el poblamiento de América, 40 mil años antes de Cristo hasta el México contemporáneo- así como la complejidad de los procesos que se pretende enseñar, no obstante, esto no se destaca como una de las causas del fracaso en el aprendizaje, al parecer, se da por hecho que el contenido y la forma como se escribe la historia es la adecuada.

\section{LA ARQUEOLOGÍA Y EL LIBRO DE TEXTO}

Para el caso que nos ocupa, la enseñanza de la historia prehispánica en el libro de texto obligatorio y gratuito para primaria, es necesario considerar que este libro se ha escrito en base a la investigación arqueológica. La información para las etapas más tempranas de desarrollo de los grupos prehispánicos proviene exclusivamente de la arqueología — disciplina que se ha dedicado

\footnotetext{
3 “México, último lugar de OCDE en educación”, La Jornada, 4 de diciembre de 2007. http://www. jornada.unam.mx/ultimas/2007/12/04/mexico-ultimo-lugar-en-educacion-ocde

4 Informe Internacional de Evaluación PISA 2006. http://www.ince.mec.es/marcosteoricospisa2006.pdf

5 Sánchez, Georgina “La OCDE: otra educación” El independiente.

http//www.lainsignis.org/2003/julio/cul 036.htm

6 Sánchez Quintanar, Andrea, Reencuentro con la Historia. Teoría y praxis de su enseñanza en México, Paideia, UNAM, México,
} 
en México, al estudio de las sociedades para las que no existe información escrita-. Para las culturas de la última época del Posclásico, se cuenta con información escrita proveniente de las crónicas de los conquistadores o de los escasos códices indígenas que han sobrevivido.

La Arqueología, de manera general, comparte el mismo objetivo que la historia, la explicación de los procesos sociales del pasado, pero a diferencia del historiador que trabaja con testimonios escritos, el arqueólogo extrae su información a partir de los restos materiales, de lo que se denomina cultura material ${ }^{7}$. Esta característica llevó a la Arqueología a construir conceptos que no son utilizados por la historia para poder explicar los procesos sociales, o que al ser utilizados al interior del discurso arqueológico, cambian su significado. Asimismo, utiliza conceptos de la Antropología, los cuales son redefinidos para adecuarlos a las características de los testimonios con los que trabaja el arqueólogo. La especificidad de la Arqueología requiere el discurso histórico del texto oficial la refleje ya que sólo así podrán ser comprendidos los procesos prehispánicos expuestos en él.

\section{Problemas para la enseñanza de la Arqueología}

El proceso de aprendizaje de cualquier disciplina está condicionado por varios factores que deben tomarse en cuenta a la hora de elaborar el material pedagógico.

- El primero de ellos tiene que ver con la naturaleza del conocimiento arqueológico,

- el segundo está relacionado con el desarrollo cognitivo del niño, y

- el tercero se relaciona con el conocimiento previo que poseen los niños al iniciar el proceso de aprendizaje.

\section{Naturaleza del conocimiento arqueológico}

La Arqueología, igual que las ciencias sociales y la historia, posee características específicas que la hacen diferente de las ciencias naturales, las cuales deben ser consideradas al elaborar los libros de texto, asimismo, es necesario considerar la forma arqueológica de interpretar la realidad y la naturaleza de este tipo de conocimiento.

El conocimiento arqueológico, como el de la Historia y las Ciencias Sociales, es más difícil de

$7 \quad$ Childe, Gordon , Piecing together the past, Routledge \& Kegan Paul, London.1969 
comprender que el producido por las Ciencias Naturales. La razón de esta dificultad se asocia fundamentalmente a la estructura de los conceptos, en las ciencias naturales son generalmente claros, precisos y pueden ser comprobados de manera experimental en cambio en las ciencias sociales la mayoría de los conceptos presentan un alto grado de abstracción, además, su significado cambia con el tiempo y en función del contexto en que se desarrollan. Otro elemento que hace más compleja la comprensión de las ciencias sociales es que la versión de un mismo acontecimiento varía en función de la posición teórica del investigador lo cual conduce a una especie de relativismo del conocimiento. La objetividad del conocimiento, aparentemente obvio en las ciencias naturales, no se puede aplicar al conocimiento producido por las ciencias sociales. Por tanto, es necesario establecer claramente la diferencia entre el conocimiento producido por las ciencias naturales y el de las ciencias sociales, para que el análisis de los procesos históricos se lleve a cabo con base en los parámetros que rigen a las ciencias sociales.

\section{Enseñanza de la Arqueología y desarrollo cognitivo del niño}

El conocimiento generado por la Arqueología ha sido reelaborado, como se señaló anteriormente, para cumplir con los objetivos pedagógicos establecidos por la SEP. Esta modificación conlleva la reescritura de la historia producida por los arqueólogos, el objetivo es que el niño comprenda los conceptos y las explicaciones de la Arqueología sobre la historia prehispánica. La reelaboración, para cumplir su cometido — que pueda ser comprendida— debe realizarse tomando en cuenta las etapas del desarrollo cognitivo del niño; así, el discurso histórico debe ser estructurado con base en lo que el niño puede descifrar a esa edad, además, debe contribuir a desarrollar las operaciones lógicas que permitirán el análisis histórico.

Para su comprensión, la historia requiere del desarrollo de habilidades cognitivas conocidas como "pensamiento formal” así como de la capacidad de entender conceptos como el de tiempo. Pero el ser humano no nace con la capacidad cognitiva que se requiere para llevar a cabo esos procesos mentales, esta se desarrolla durante el crecimiento biológico, y es hasta la adolescencia cuando se adquieren plenamente estas habilidades ${ }^{8}$

Esta realidad biológica condujo en determinado momento a plantear que la enseñanza de la historia debía iniciar hasta la adolescencia, pero el proceso de adquisición de estas habilidades no implica que surjan, de manera espontánea, en la adolescencia. Este proceso está íntimamente

$8 \quad$ Carretero, Mario. "Perspectivas disciplinares, cognitivas y didácticas en la enseñanza de las Ciencias Sociales y la Historia”, en Construir las Ciencias Sociales y la Historia, Buenos Aires, AIQUE. 2002:15 
relacionado con el tipo de instrucción que el ser humano recibe durante su desarrollo, ${ }^{9}$ por tanto, la introducción de los conceptos históricos en los niños debe de realizarse de manera muy cuidadosa, tomando en cuenta el contenido de ellos y la etapa de desarrollo cognitivo, de no ser así, el aprendizaje se quedará solamente en el nivel del conocimiento declarativo (aprendizaje memorístico) restringido a la repetición de fechas y nombres, y no podrá desembocar en un aprendizaje que permita la aplicación de esos conceptos de manera constructiva.

\section{Construcción de conceptos}

La teoría sobre la construcción de conceptos, considera que la elaboración de éstos se produce de manera progresiva, es decir, se construyen durante las diferentes etapas del desarrollo cognitivo. ${ }^{10}$ Con base en estos estudios, la introducción de los conceptos históricos en los niños se puede iniciar desde las primeras etapas del desarrollo infantil siempre y cuando el contenido se adecue al nivel del desarrollo cognitivo. Esta propuesta se encuentra estrechamente ligada a lo que se ha llamado el conocimiento previo que poseen los niños al iniciar su proceso de aprendizaje.

\section{Conocimiento previo}

El proceso de enseñanza y aprendizaje no depende exclusivamente del desarrollo de las habilidades cognitivas o del proceso de comprensión de conceptos, sino también obedece al tipo de información, o conocimiento previo con el que se aborda lo que no se conoce. El proceso de socialización del ser humano implica el aprendizaje del mundo que lo rodea desde el momento mismo de su nacimiento. El conocimiento del medio es vital para su sobrevivencia, la clasificación y explicación de los fenómenos con los que se enfrenta el niño, cotidianamente, desde su nacimiento, le son proporcionados por la sociedad en la que está inmerso y se le presentan como algo obvio y natural. A menudo, este conocimiento cotidiano, producto de la experiencia inmediata que sirve eficazmente para sobrevivir o funcionar de manera exitosa, no corresponde a la explicación que se recibirá durante el proceso de enseñanza formal.

$9 \quad$ "Y si bien es cierto que se observa en los alumnos una progresión en la complejidad de las respuestas con la edad, no es menos cierto que el paso del tiempo garantice que los alumnos adquieran estas complejas nociones temporales. Más bien parece que si estos alumnos no son sometidos a una instrucción adecuada no van a adquirir estos conceptos” Cristofol Trepat, Procedimientos en historia, un punto de vista didáctico, Barcelona, Grao. 1999

10 Camilloni, Alicia. “Sobre la programación de la enseñanza de las ciencias sociales” http://redescolar. ilce.edu.mx/redescolar/biblioteca/articulos/pdf/sept_capit.pdf 
La enseñanza de la Arqueología en la educación básica, debería de estar enfocada a proporcionar a los niños las herramientas conceptuales que les permitan comprender las características del proceso de producción de conocimientos propio de esta disciplina. Parafraseando a Pluckrose tienen que ser conscientes "de lo que significa ser un arqueólogo", para que puedan posteriormente saber cómo "plantearse el pasado". ${ }^{11}$

\section{Objetivos de la enseñanza de la historia en la primaria}

El objetivo de reintroducir la enseñanza de la historia como materia independiente se basó, según la SEP, 12 "en el valor formativo que tiene esta disciplina, su enseñanza aporta [...] valores éticos personales y de convivencia social” necesarios para la vida en sociedad, al mismo tiempo coadyuva a la formación de la identidad nacional, se pretende también, que mediante su enseñanza, los niños conozcan la historia de su país además de desarrollar la:

[...] capacidad para comprender procesos históricos, la dinámica del cambio social, el papel que desempeñan los individuos y los diferentes grupos sociales en la historia. Es decir, se pretende propiciar la formación de la conciencia histórica de los niños al brindarles los elementos que analicen la situación actual del país y del mundo como producto del pasado ${ }^{13}$

Para cumplir con los objetivos perseguidos por la SEP con la enseñanza de la historia, es necesario que el discurso histórico del libro de texto le permita al estudiante comprender los procesos históricos así como entender la forma como el arqueólogo construye la explicación histórica. No basta con mejorar la calidad del magisterio ni con modificar los sistemas pedagógicos, es necesario contar con un libro de texto que permita lograr este propósito. El programa de Historia para primaria se estructuró a lo largo de los seis grados que comprende este nivel educativo, y se desarrolla de menor a mayor complejidad. En los dos primeros años, primero y segundo grado, se introduce al niño en los conceptos fundamentales para la comprensión de los procesos históricos: las nociones de tiempo y espacio; en el tercer grado se inicia el estudio de 11 "Si los niños tienen que estudiar historia y extraer algún sentido de ello, se les debe ayudar a ser conscientes de 'lo que significa ser un historiador' [...] Una vez desarrollada una comprensión de cómo plantearse el pasado, las técnicas adquiridas de esta forma pueden aplicarse a cualquier momento del pasado (tanto reciente como lejano) y a cualquier lugar [...]” Pluckrose, Henry. Enseñanza y aprendizaje de la historia, Madrid, Ediciones Morata, S. L. 1996: 17

12 SEP, Planes y Programas de Estudio 1993, Educación Básica Primaria, México, SEP.1993:91

13 SEP Libro para el maestro, Historia cuarto grado, México, SEP. 1996:8 
la historia junto con la geografía, en el cuarto grado se imparte la historia de México desde la prehistoria hasta la época actual, en quinto se estudia la historia de México desde la prehistoria hasta la independencia junto con la historia universal, y en sexto se enseña la historia de México desde la independencia hasta el presente.

El objetivo específico en los dos primeros grados de primaria, es que los niños conozcan la noción de espacio y del cambio a lo largo del tiempo además de familiarizarse con los principales sucesos de la historia de México. Para tal propósito, el libro de texto de estos años integra los conocimientos de las materias de Historia, Geografía, Ciencias Naturales y Educación Cívica en una sola materia llamada Conocimiento del Medio.

Los conceptos de cambio y tiempo se enseñan mediante las transformaciones del propio niño durante su proceso de crecimiento y con los cambios en su entorno (familia, casa, barrio, ciudad), es decir, se parte de lo conocido, de lo cercano al niño, para ayudarle a construir los conceptos. El conocimiento sobre la historia se lleva a cabo por medio de las celebraciones cívicas que contiene el calendario escolar: el desarrollo del libro va intercalando el aprendizaje de los conceptos con la información histórica relevante al hecho que se conmemora. Como apoyo didáctico para el desarrollo del programa, la SEP proporciona a los maestros el Libro para el Maestro, en el cual se le suministran propuestas didácticas para apoyarlos en el proceso de enseñanza, además del Avance Programático que auxilia al maestro a planear la enseñanza.

En tercero, cuarto y quinto de primaria, se estudia la historia de México siguiendo un enfoque cronológico, es decir, se inicia con lo más lejano en el tiempo: el poblamiento de América y se hace un recorrido histórico desde los grupos cazadores recolectores hasta el México actual.

En el tercer grado de primaria inicia el estudio "sistemático" de la historia, en este nivel se enseña la historia de la entidad federativa y se refuerzan los conceptos de tiempo y espacio que se estudiaron en los dos primeros grados. En el cuarto grado, a manera de un "curso general e introductorio”, se imparte la historia de México; en el quinto grado se enseña la historia de México hasta la Independencia, y la historia universal; en sexto grado el programa parte de la Independencia y termina con el México contemporáneo. 
El contenido del programa para la historia prehispánica en tercero, cuarto y quinto es prácticamente el mismo, excepto que para el tercer grado los hechos históricos se refieren a la historia de la entidad. La enseñanza de la historia en estos tres años, tiene como objetivo capacitar a los niños para que apliquen los conceptos adquiridos en los dos primeros años y sean capaces de interpretar los hechos históricos, es decir, que sean capaces de reflexionar sobre ellos para entender sus causas y sus consecuencias. Al finalizar la primaria, el estudio sistemático de la historia debe de haber contribuido a conformar en el niño las habilidades cognitivas necesarias para la utilización de las nociones históricas "[...] como las de causalidad, influencia recíproca entre fenómenos, difusión de influencias y diversidad de procesos históricos y formas de civilización, con el propósito de que les sirvan para el [...] análisis de la vida social contemporánea” ${ }^{14}$ La narración histórica introduce, desde el tercer grado, una serie de conceptos para explicar lo que ocurrió en el pasado con el objetivo de que los niños entiendan las causas de los procesos sociales y sus consecuencias.

La complejidad de los procesos que se narran durante el nivel primaria requiere del uso de numerosos conceptos, algunos de ellos pertenecen solamente al dominio de la Arqueología y son claves para entender el discurso arqueológico.

Algunos de los conceptos que manejan los arqueólogos relacionados con el tiempo y el espacio carecen de utilidad como herramientas de análisis y explicación y sirven solamente — como en el caso del esquema de la periodización: Preclásico, Clásico y Posclásico—como marco cronológico para evitar el recurso a la utilización constante de fechas y en el caso de Mesoamérica funciona principalmente como una delimitación espacial, que, para propósitos de divulgación general, se asocia generalmente con las fronteras actuales de México, a pesar de que es un concepto muy complejo y controvertido.

La estructura de las sociedades prehispánicas es definida por los arqueólogos mediante la utilización de conceptos que clasifican a las sociedades en función de su complejidad, a continuación analizaremos algunos de los conceptos según aparecen en el discurso narrativo de la historia prehispánica en el libro de texto:

- Mesoamérica: manejo del espacio,

14 SEP, Planes y Programas de Estudio 1993, Educación Básica Primaria, México, SEP.

1993. 
- Preclásico: temporalidad y periodización,

- Aldeas y Ciudad: formas de organización social.

\section{Mesoamérica}

Este concepto se define en el libro de texto tomando como criterio principal la presencia o ausencia de agua y se presenta en oposición al concepto de Aridoamérica, en donde la falta de agua hizo que los pobladores continuaran como nómadas o seminómadas, en el recuadro de esta lección en el libro de cuarto se dice:

Mesoamérica o América media, es esa zona verde que abarca las tierras más húmedas de México y parte de Centroamérica. Al norte se extiende Aridoamérica que es más árida porque ahí llueve poco. Las diferencias de clima influyeron para que las dos regiones tuvieran formas de vida distintas ${ }^{15}$

También se anota que los grupos establecidos en Mesoamérica compartían modos de vida: cultivaban maíz, frijol, calabaza y chile, usaban la coa, practicaban religiones semejantes y tenían los mismos dioses pero con diferente nombre. En el libro de quinto, se amplía el concepto y se explica la mesoamericanización de las sociedades:

[...] el comercio, las migraciones y las expediciones militares difundieron la influencia de los pueblos más avanzados. Por eso hay costumbres y formas de trabajo que son comunes a todos los pueblos de Mesoamérica ${ }^{16}$

La definición de Mesoamérica en el libro de texto se reduce a un concepto que explica el desarrollo cultural mediante el determinismo ecológico, presencia o ausencia de agua; además, lleva implícito el principio de que la cultura se desarrolla solamente en determinadas sociedades, las cuales son definidas como "pueblos más avanzados" y de ahí se expande hacia otros pueblos. A partir de esta definición, se describe el desarrollo de los pueblos que habitaron esa zona siguiendo la periodización Preclásico, Clásico y Posclásico. En los libros de cuarto y quinto se señala la separación de los periodos — primeros pobladores a sociedades mesoamericanasporque se inicia un nuevo bloque; en el libro de cuarto a las sociedades mesoamericanas de les titula: El México Antiguo, en el libro de quinto grado, El Esplendor de Mesomérica. En el de $15 \quad$ SEP.Historia Cuarto Grado, México, SEP. 1996:15

16 SEP.Historia, Quinto Grado, México, SEP. 1994:90 
tercero no se establecen estas divisiones, sino que se hace una narración, sucinta y sin cortes, de los pueblos de la cuenca de México.

\section{Preclásico}

El estudio de las culturas prehispánicas organizadas al interior de estos periodos se justifica por el hecho de que en cada una de esas épocas "los pobladores comparten más o menos el mismo nivel de desarrollo cultural"17, durante este periodo, “comenzaron a consolidarse las culturas de Mesoamérica” ${ }^{18}$ la fecha que se registra para consignar la aparición de "aldeas agrícolas permanentes” es el año 1500 a. C. Este dato es erróneo y se repite en los libros de cuarto y quinto; el inicio del Preclásico ha sido fechado ${ }^{19}$ hacia el año 2500 a.C. o cuando menos 2300 a.C. La presencia o ausencia de ciertos rasgos culturales, como la construcción de pirámides, y el hecho de que esos elementos se encontraron “debajo” de los centros ceremoniales del Clásico es lo que justifica la definición del Preclásico. Se le caracteriza, además, como la época para la cual “comenzaron a consolidarse las culturas de Mesoamérica” al describir su forma de vida simplemente se enumeran las actividades que realizaban: “sembraban, iban de cacería, tejían canastas, fabricaban vasijas [...] intercambiaban productos con habitantes de otras aldeas [...]”, pero no se establece ningún tipo de jerarquización entre los elementos utilizados para definir este periodo y describir su forma de vida. De esta manera no es posible determinar cuáles son los elementos fundamentales que nos permiten clasificar a las sociedades y tampoco se puede entender cuáles son las principales causas que producen, en un momento dado, el cambio social Para los arqueólogos Mesoamérica es una región (área cultural) en la cual sus habitantes comparten un mismo patrón de subsistencia: la agricultura, tienen una tradición compartida y una historia común. Si comparamos la definición del libro de texto con la producida por la Arqueología, vemos como en el libro de texto, se pierde la clave que permite definir este concepto: la adopción de la agricultura como base fundamental para la subsistencia; el cambio en el modo de subsistencia, implica además una transformación en las formas de organización social. A pesar de que los arqueólogos suscriben diferentes teorías sobre el desarrollo social, todos coinciden en señalar,

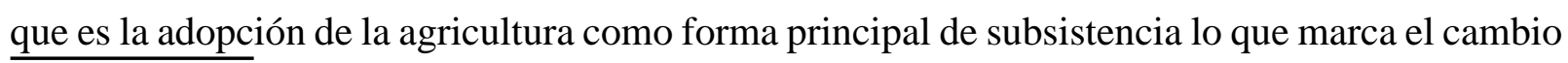
$17 \quad$ Ibid.

18 SEP.Historia Cuarto Grado, México, SEP. 1996a:19

19 López Austin Alfredo y Leonardo López Luján, El Pasado Indígena, México, Fondo de Cultura Económica. 1996 
de un periodo a otro, y el indicador arqueológico que marca el inicio de este periodo es la cerámica, ${ }^{20}$ no la construcción de pirámides.

En el libro de texto se menciona que durante el Preclásico, [...] la población aumentó y las aldeas se convirtieron en ciudades" lo cual implica una transformación de sociedades igualitarias a sociedades estratificadas. Para la Arqueología, las aldeas ${ }^{21}$ son:

[...] poblaciones completamente sedentarias, cuyo medio principal de subsistencia era la agricultura...la organización social [...] siguió siendo básicamente de carácter igualitario [...] Cada aldea era autosuficiente [pero existían] redes de intercambios [estos se realizaban] probablemente por trueque ${ }^{22}$

El concepto de ciudad se utiliza para caracterizar sociedades con alta densidad de población, concentrada en centros urbanos, es decir, asentamientos construidos con un plano regulador, que presentan un alto grado de división del trabajo, además de constituir la sede de la administración política, religiosa y militar, el lugar donde se toman las decisiones, generalmente el término de ciudad está asociado al concepto de Estado.

Como vemos la complejidad de los procesos sociales que se desarrollaron durante el Preclásico no se refleja en el libro de texto, la Arqueología para poder dar cuenta de estas transformaciones ha dividido internamente este periodo de la siguiente manera:

- Preclásico Temprano 2500 a 1200 a.C. Inicio de la agricultura y la cerámica. Concentración en caseríos y aldeas, sociedades igualitarias.

- Preclásico Medio 1200 a.C. a 400 a.C. Sociedades con diferenciación social y jerarquías basadas en el linaje.

- Preclásico Tardío 400 a.C. a 150/200 d.C. “Complejidad socioeconómica creciente. Desarrollo de la organización política. Surgimiento de capitales protourbanas como

20 "Cuando los arqueólogos, con su particular terminología, afirman haber llegado a una capa precerámica, se están refiriendo a los estratos más antiguos de la historia humana. En ellos encontrarán los vestigios de la época en que sólo existían las sociedades de recolectores-cazadores. En cambio, por la presencia de la cerámica en capas menos profundas distinguen estadios de desarrollo cultural: los de la vida sedentaria.” Ibid, 76.

21 El concepto de Aldea, también fue utilizado para caracterizar a las poblaciones del segundo subperiodo: Primeras Aldeas, del bloque los Primeros Pobladores, pero no se explica su significado.

22 García Bárcenas, Joaquín Historia Gráfica de México I, Época Prehispánica, México, INAH, Editorial Patria. 1998:58 
densos centros regionales con aldeas satélites. ${ }^{23}$

Las causas del cambio de las sociedades del Preclásico, en la narración del libro de texto, se asocian al devenir temporal, "Al paso del tiempo la población aumentó y las aldeas se convirtieron en ciudades [...]”, es simplemente la acumulación de pequeños cambios al interior de las sociedades lo que conduce a cambios cualitativos; o se dice que "Durante el Preclásico creció considerablemente la población de Mesoamérica [...hubo] una explosión demográfica [...]”; en ambos casos se produce la impresión de que son elementos ajenos a la voluntad de los seres humanos los causantes del cambio social; no son las sociedades las que producen las transformaciones, sino más bien, se adaptan a fenómenos producidos fuera de la esfera de la acción humana. La diferenciación social, es también una consecuencia natural del paso del tiempo; al crecer las aldeas se transforman en ciudades y la población tiene que diversificar sus actividades, así unos se hacen gobernantes y otros campesino, etcétera. Una transformación pacífica e idílica que presenta como algo natural las relaciones de dominación.

En el libro de texto, no se intenta estructurar una explicación que contemple diferentes causas y que manifieste las contradicciones inherentes a las sociedades estratificadas, en cambio para la Arqueología, la explicación de las causas de la transformación social, varían en función de la teoría que sustenta el arqueólogo, y suelen ser complejas, por ejemplo, López Austinn ${ }^{24}$ menciona:

Son varias las hipótesis que pretenden explicar el surgimiento de la diferenciación social. Cada una atribuye este trascendental cambio a una causa distinta: el acceso diferencial a los recursos naturales originado por el incremento demográfico; el desarrollo tecnológico; el conocimiento de fenómenos naturales básicos para la producción agrícola; la coordinación de obras hidráulicas comunales; el control del intercambio regional y la redistribución de los productos alóctonos, o el manejo de la sobrenaturalaza.

23 Esta periodización ha sido tomada de López Austin, Alfredo y Leonardo López Luján “Tiempo Mesoamericano (2500 A.C.-1521 D.C.) Periodos, Regiones y Culturas Prehispánicas”, en Arqueología Mexicana, edición especial, núm. 11, México, Raíces. 2002

24 López Austin Alfredo y Leonardo Lóéz Luján. El Pasado Indígena, México, Fondo de Cultura Económica.

1996:78] 
La construcción de conceptos mediante el libro de texto no les proporciona a los niños los criterios necesarios para delimitar el sentido de las palabras que se utilizan ni les ayuda a entender el significado en su contexto histórico. Así, al no definir conceptos como aldea o ciudad se da por sentado que su significado es conocido y evidente, esto causa una interpretación de esos conceptos, por parte de los niños, en función del significado moderno. ${ }^{25} \mathrm{Si}$ a esto le añadimos los errores en las fechas, utilizar el concepto Preclásico, en lugar de ayudar a entender los procesos sociales, produce confusión además de fomentar concepciones erróneas para la comprensión de la historia.

Para ejemplificar el desarrollo en el Preclásico, se eligió la cultura Olmeca, definida como la "primera gran cultura mesoamericana", se les describe como notables escultores que construyeron centros religiosos con una organización social integrada por gente común, gobernantes y sacerdotes. La definición de los olmecas se estructura en los mismos términos que se describe al Preclásico: se enumeran los rasgos que distinguen esa cultura, tomados básicamente de lo que en la actualidad se denomina arte, es decir, de su escultura, y se les asigna el papel de creadores de la primera Gran Cultura, la cual fue difundida por toda Mesoamérica. El surgimiento de esta cultura se debió a las condiciones óptimas del medio ambiente en el cual se desarrollaron: lluvias abundantes, ríos caudalosos, tierras fértiles.

Este esquema simplista, deja de lado las explicaciones que la Arqueología ha propuesto, y oculta la complejidad de lo que se llama Olmeca. Este término define básicamente un estilo artístico: “[...] un estilo en escultura y cerámica, así como la presencia de ciertos materiales que, como la magnetita y la jadeíta, fueron profusamente utilizados en la zona del sur de Veracruz y Tabasco, aparentemente para propósitos de diferenciación social”26 En los asentamientos olmecas de la costa del Golfo, se han encontrado los rasgos que caracterizan a sociedades con un alto grado de diferenciación social, la dispersión de los rasgos olmecas por el territorio mesoamericano se ha explicado en función de una red importante de intercambio de bienes suntuarios, necesarios para

$25 \quad$ El significado de los conceptos utilizados en las ciencias sociales cambian con el tiempo y en función del contexto en el cual se desarrollan, como se mencionó anteriormente, por eso es necesario definir claramente los conceptos utilizados en la narración histórica. De otra manera, los niños tenderán a extrapolar el significado de esos conceptos, a partir de los conocimientos que posean sobre la sociedad contemporánea.

26 Nalda, Enrique “México Prehispánico: origen y formación de las clases sociales”, en Semo, Enrique (coord.), México un pueblo en la historia, tomo I, México, Alianza Editorial (col. El libro de bolsillo). 1989:60 
reforzar las posiciones de prestigio en la sociedad. Ninguno de estos elementos se menciona en la descripción de lo olmeca, y la imagen que se introduce a los niños, es la de la Cultura Madre de Mesoamérica. Se refuerza así la imagen de que solamente un grupo de privilegiados produce la civilización la que es difundida y asimilada por las otras culturas, que de no haber sido así no hubiesen podido desarrollarla.

\section{La imagen en el libro de texto}

El discurso histórico en el libro de texto de primaria se estructura combinando texto, actividades e imagen; el potencial pedagógico de las imágenes ha propiciado su uso en los libros de texto escolares. En México, a partir de la reforma educativa de 1992, la SEP incrementó la cantidad de imágenes en los libros con el propósito de ayudar "a entender la información” contenida en ellos y al mismo tiempo contribuir a que los estudiantes se familiaricen con algunas de las obras de arte que conforman el patrimonio cultural mexicano. La imagen tiene además una connotación especial: por el solo hecho de aparecer en un texto pedagógico es un documento que nos muestra la realidad. Un libro de texto, por ser utilizado como parte del sistema educativo, está dotado de una autoridad moral que hace que la información vertida en el libro no sea cuestionada. ${ }^{27}$

El proceso de aprendizaje por medio del libro de texto implica la comprensión del discurso histórico conformado por el texto y la imagen, así, se pasa de la imagen al texto y viceversa conformándose el sentido del discurso por la interrelación de sus elementos.

La comprensión de una imagen puede parecer, a primera vista, más sencilla que la de un texto escrito, de manera general se asume que es más fácil comprender una imagen ya que no se necesita conocer las palabras, se considera evidente su significado. La imagen, en el libro de texto, adquiere sentido en función de la información asociada a ella, de la posición que ocupa en la página y del título de la imagen. Sin embargo, la comprensión de una imagen en el libro de texto de historia, no depende solamente de los elementos mencionados, es necesario reconocer que una imagen responde a una serie de convenciones culturales que el autor recrea y proyecta por medio de ella, por lo que es necesario entender el contexto cultural del cual proviene; por otro lado, el bagaje cultural del receptor, en este caso el niño, condiciona la forma de interpretar la 27 Choppin, Alain "Las políticas de libros escolares en el mundo: Perspectiva comparativa e histórica”, en Pérez Siller, Javier y Verena Radkau García, (coords.), Identidad en el imaginario nacional reescritura y enseñanza de la historia, México, BUAP, El Colegio de San Luis, A. C., Instituto Georg-Eckert (Alemania),1998:169-170 
imagen lo que puede conducir a la construcción de significados que no necesariamente coinciden con el propósito del libro.

En el libro de texto de historia, a partir del tercero de primaria, las imágenes utilizadas para la historia prehispánica, son en su mayoría fotografías de los restos de la cultura material de los grupos que habitaron el territorio mexicano: arquitectura, cerámica, obsidiana, pintura mural, escultura, códices o reproducciones de obras de arte que recrean escenas del pasado. Estas imágenes representan una visión del mundo diferente a la de nuestra sociedad contemporánea, de ahí que la comprensión de su significado no necesariamente resulte evidente para el lector.

\section{Percepción visual}

De manera general se acepta que mediante la vista se obtiene una imagen "real" del mundo que nos rodea. Esta afirmación se basa en el hecho de que la visión es un proceso fisiológico que, independientemente de la raza, género o cultura, permite a los seres humanos percibir la realidad del mundo que lo rodea. La visión es un proceso mediante el cual el cerebro recibe señales luminosas de los objetos y las interpreta, pero el significado que se genera a partir de esas imágenes está en función de los códigos culturales del sujeto ${ }^{28}$. Estos códigos, están determinados por las condiciones históricas que conforman a la sociedad.

La comprensión de imágenes producidas por culturas diferentes a las nuestras tiene que ser analizadas en función de la concepción del mundo ${ }^{29}$ en la que fueron producidas. Para evaluar el potencial educativo de una imagen que se inserta en un libro de texto es necesario tomar en cuenta que las imágenes son un medio de comunicación que responden a una cosmovisión producto de procesos históricos específicos y que no transmiten valores universales, por tanto, su análisis depende de conocer el contexto en el que fueron creadas y su propósito.

\section{LECTURA DE IMÁGENES EN EL LIBRO DE TEXTO}

En el libro de texto de historia el sentido del discurso histórico se forma por la interacción entre el texto escrito y las imágenes, su lectura implica un constante ir y venir entre el texto

28 González Ochoa, César .1997Apuntes acerca de la representación, México, UNAM.

29 La concepción del mundo que posee una sociedad impone normas que rigen la producción de imágenes y condicionan su interpretación. 


\section{ON9 $9^{\circ}$ CONGRESO \\ 9 \& CENTROAMERICANO

Indexaciones: Repositorio de Revistas UCR, DIALNET, Latindex, REDALYC Directorio y recolector de recursos digitales del Ministerio de Cultura de España, Directory of Open Access Journals.

Diálogos Revista Electrónica de Historia ISSN 1409-469X. Número especial 2008. Dirección web: http://historia.fcs.ucr.ac.cr/dialogos.htm

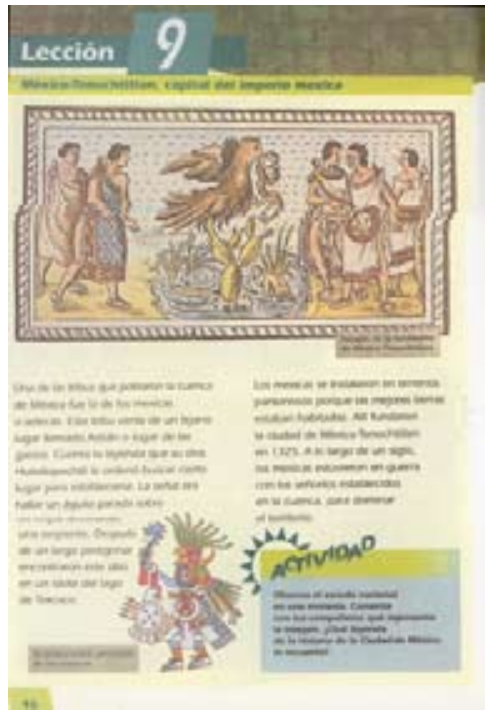

Libro de Tercero de Primaria

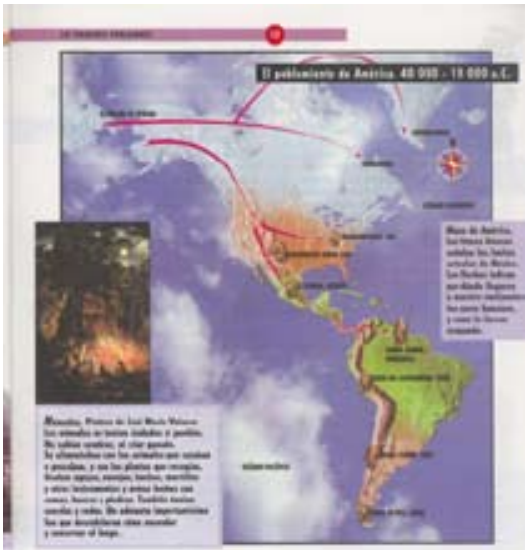

Libro de Cuarto de

Primaria

$\cdot$ - atu
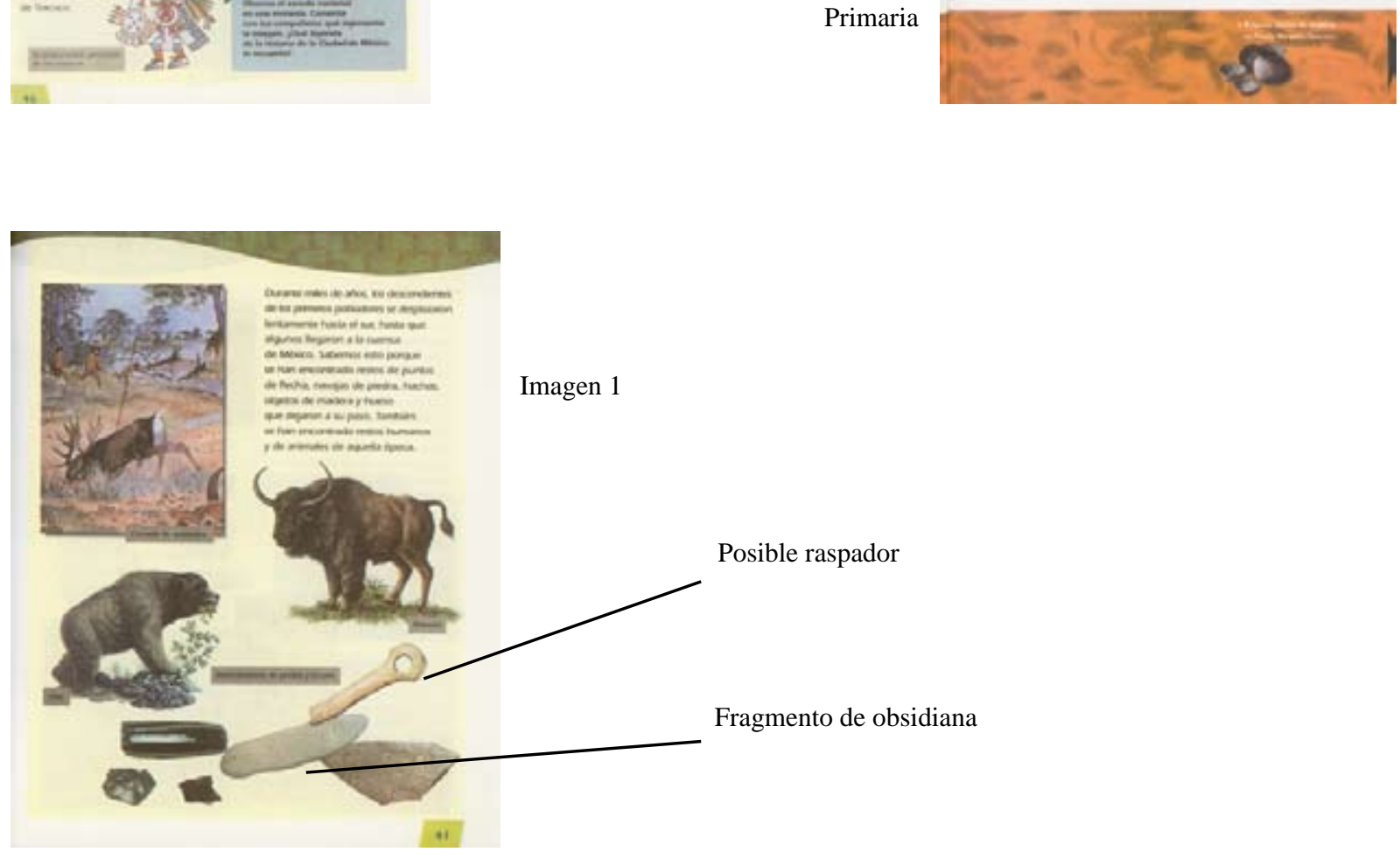

y la imagen y, a pesar de que en principio el texto es el que le confiere el significado a la imagen, también ellas pueden cambiar el significado del texto.

Los libros de historia de primaria contienen una gran cantidad de imágenes, cada una de las páginas de los libros tiene aproximadamente $50 \%$ de texto y $50 \%$ de imágenes, como se puede apreciar en las reproducciones de algunas páginas de los libros de texto.

Las imágenes han sido seleccionadas para que contribuyan a una mejor comprensión del texto y 
para que los niños conozcan los aspectos de la vida social, el paisaje y el arte que no se explican en el texto. Por tanto, es de esperarse que las imágenes deben de corresponder al tema tratado.

En el libro de tercero, en la lección 8 De las aldeas a las ciudades, las imágenes incluidas en las dos primeras páginas se relacionan con el poblamiento de América y las actividades de caza y recolección (imagen 1), asimismo, se reproducen instrumentos de piedra y hueso.

En el texto ${ }^{30}$ se menciona que se han encontrado "restos de puntas de flecha, navajas de piedra, hachas, objetos de madera y hueso que [los primeros pobladores] dejaron a su paso" sin embargo las imágenes mostradas contienen un conjunto de objetos que no corresponden con lo mencionado en el texto, podemos observar un núcleo, talvez un raspador, (la imagen no es muy buena, por lo que no es posible afirmar con certeza cual es el tipo de artefacto reproducido) un desecho de obsidiana, piedra y hueso con incisiones, pero no hay navajas, puntas de flecha o hachas. El título de la imagen indica que los objetos representados son: Instrumentos de piedra y hueso, pero no los identifica, tampoco se señala su procedencia, uso o tamaño.

En el libro de cuarto, para el mismo periodo, Lección 1, Los primeros pobladores, se eligió una especie de collage, que combina los elementos con los que se pretende caracterizar este periodo.

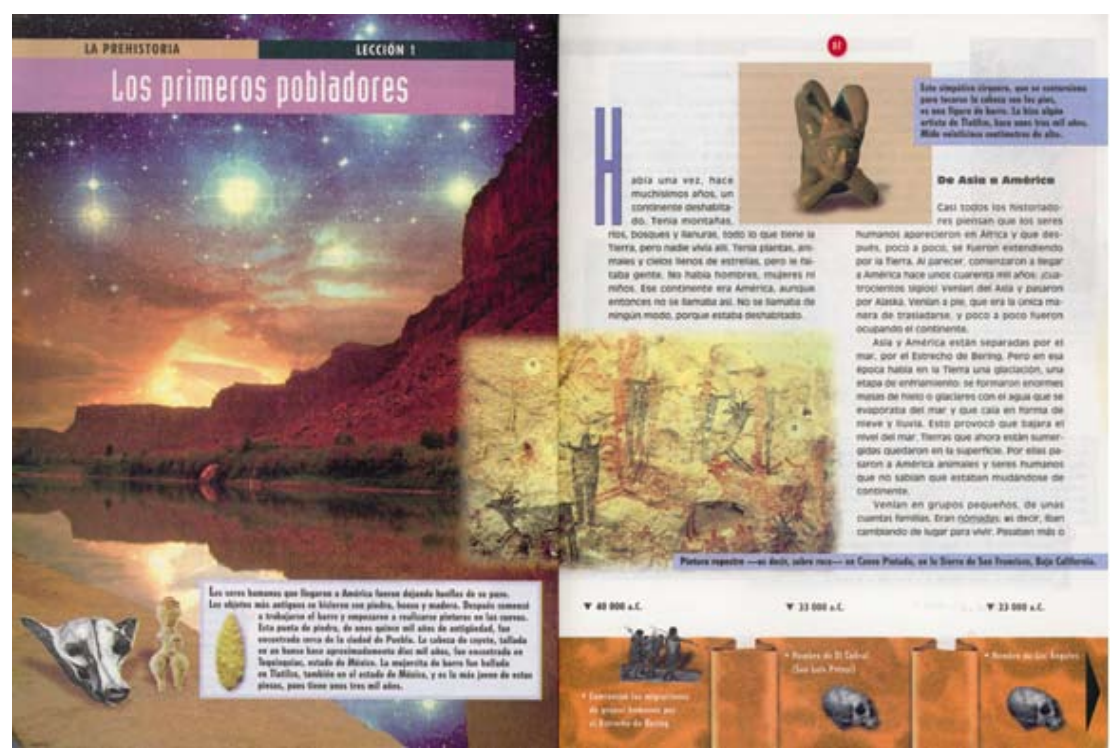


Como se puede apreciar en la imagen 3 se ha integrado paisaje, pintura rupestre, hueso, figurillas de cerámica y puntas de proyectil, estas imágenes corresponden a dos periodos diferentes, por un lado, la pintura rupestre, la punta de flecha y el hueso tallado corresponden a un etapa de caza-recolección asociada al nomadismo, en cambio la cerámica pertenece a grupos agrícolas, el recuadro de la página izquierda proporciona la información que permite ubicar cronológicamente estos objetos, pero tanto el título de la lección Los primeros pobladores y el texto hablan de los primeros grupos humanos, es decir, de nómadas con una economía basada en la caza y la recolección.

De esta manera, se puede producir una representación ${ }^{31}$ errónea que conformará una imagen de la etapa de caza-recolección, la cual incluirá entre los rasgos que caracterizan a este periodo a la cerámica, éste es el indicador utilizado por los arqueólogos para reconocer el tipo de organización social que caracteriza la vida sedentaria y que marca el inicio de lo que se ha denominado revolución neolítica, cambio radical en el desarrollo de las sociedades. El maestro tiene que explicar que las imágenes de cerámica se han incluido para propósitos de especificar una secuencia cronológica y no corresponden al periodo del que trata la lección.

Por otro lado, aún cuando la pintura rupestre incluida en el collage, corresponde a un periodo de caza-recolección, fue realizada en fechas relativamente recientes (7000-5000 a.C.) y el texto asociado a la imagen se refiere al periodo comprendido entre los años 40000 y 23000 a.C., como lo indica la línea del tiempo en la parte inferior de la página derecha.

Al doblar la página, en la esquina superior izquierda, imagen 4, se encuentra la pintura Cazadores de osos de José María Velasco y en la parte inferior derecha, una fotografía del diorama que se encuentra en el Museo de Antropología, el cual representa la Cacería del mamut hace doce mil años. Tanto la pintura como el diorama se hicieron en una época en la cual se consideraba que estos grupos se dedicaban a cazar este tipo de animales, pero la información disponible al momento en que se escribió el libro, 1992, había descartado esta interpretación, en cambio, mediante estas imágenes se refuerza una versión que la Arqueología dejó de lado por ser inexacta.

31 De manera general se entiende por representación "[...] un proceso por medio del cual se instituye un representante que, en un cierto contexto, ocupa el lugar de lo que representa” González Ochoa, César Apuntes acerca de la representación, México, UNAM. 1997:31 


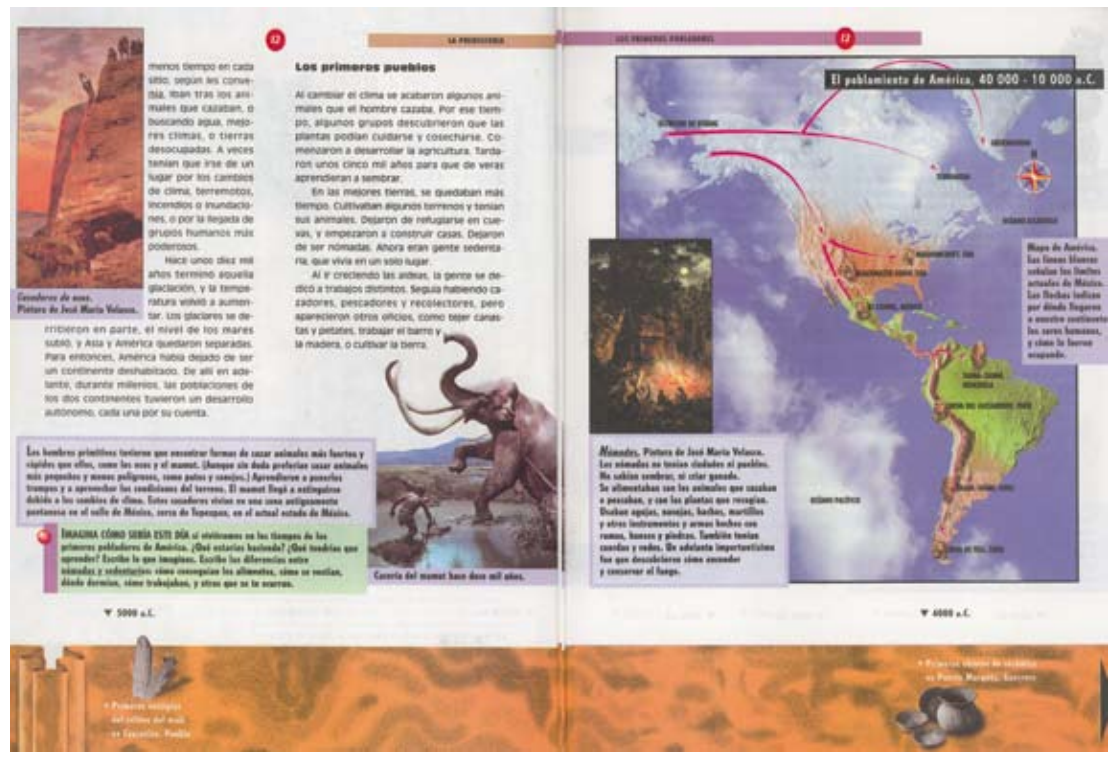

Imagen 4

Es importante destacar, que este tipo de imagen puede ser considerado por los niños como una representación de la realidad. Un estudio llevado a cabo por Mario Carretero y María Fernanda González $^{32}$ en el cual analizaron la forma en que los niños llevaron a cabo la descripción de una imagen, el grabado de T. De Bry que muestra el momento en que Colón llegó a América, indica que los niños menores de 12 años pueden interpretar éstas imágenes como lo que en realidad aconteció:

Los resultados que obtuvimos no muestran diferencias significativas entre sujetos de distinta procedencia, pero sí al realizar las comparaciones por edad. Comprobamos que más de la mitad de los entrevistados de 12 años ven la imagen como una copia directa del evento representado. Podemos decir que creen que efectivamente el descubrimiento de América sucedió así, como se muestra en el grabado. Muchos, al describir la imagen, hablan de la "foto", y ninguno de ellos utiliza elementos del contexto de producción de la imagen para interpretarla.

A esta forma de leer una imagen la han denominado Lectura realista ingenua, ${ }^{33}$ y desaparece 32 Carretero, Mario y María Fernanda González . “Imágenes histórica y construcción de la identidad nacional: una comparación entre la Argentina, Chile y España” en Carretero, Mario y James F. Voss comps Aprender y pensar la historia, Buenos Aires, Amorrortu, 2004: 173-195.

33 "Lectura realista ingenua: la imagen es entendida como una copia de la realidad; el autor es percibido como testigo directo de los hechos que registra instantáneamente y los sucesos no cambian al ser pintados o grabados, sino que <<sucedieron asís>; se borra el proceso de producción del grabado, y la lectura se hace de manera directa, sin contextualizar [Burke, P., 2001]; coinciden el grabado (producto cultural) y la realidad, solapados. En términos generales, el sujeto no cuestiona críticamente la imagen, sino que le $<<$ cree $>>$ 
alrededor de los 14 años. Según estos mismos investigadores, solamente en los adultos se dieron lecturas contextualizadas, es decir, se consideró a la imagen como un "producto histórico y cultural" que debe ser interpretada "teniendo en cuenta su contexto de producción y su uso actual"

La lectura de imágenes en los libros de texto de primaria, la llevarán a cabo niños menores de 12 años, que tenderán a interpretarlas como "lo que en realidad pasó” por lo que lejos de ayudar a entender la forma de vida de los primeros pobladores, se está induciendo una representación distorsionada, al margen de las interpretaciones arqueológicas.

\section{Conclusiones}

El análisis de los conceptos anteriores permite señalar lo que, según mi opinión, son los problemas que presenta la estructura del discurso pedagógico del libro de texto de historia.

Si tomamos en consideración que la arqueología construye sus explicaciones en función de la teoría que suscribe el investigador, la explicación contenida en el discurso narrativo arqueológico, necesariamente contiene la enunciación del acontecimiento - implica una definición clara y concisa de los conceptos utilizados-, explicita, además, la relación entre los acontecimientos, hace inteligibles sus conexiones y expresa de manera inequívoca las causas del cambio, es decir, muestra cómo interactúan los diferentes elementos en los procesos sociales y cuáles, en determinado momento actúan como detonantes. Además, la construcción del pasado se produce al interior del discurso su significado se encuentra en la narración arqueológica, el aislar los conceptos de la matriz en la que se estructuran, conduce a una pérdida del sentido o del significado de ese concepto.

La reescritura de la historia prehispánica para el libro de texto tiene que ser muy cuidadosa en este aspecto, pero lo que se observa en la narración analizada, es precisamente lo contrario. Los conceptos utilizados, en la mayoría de los casos no se definen, y se sacan de su contexto, por ejemplo vemos que se utilizan los conceptos de tribu, aldea, imperio, señorío, estado, ciudad, entre otros. Estos pertenecen a diferentes teorías, es decir a formas disímiles de explicar o interpretar la realidad, así, por ejemplo, el concepto de tribu forma parte de la secuencia: banda, tribu, cacicazgo, Estado, del evolucionismo cultural utilizado por Sanders y Price en su libro ingenuamente, y puede comentar, por ejemplo: $<<$ (El pintor) por ahí estuvo en el momento y quiso captarlo de inmediato. ¿Por qué? Porque él quería guardar ese momento >> Ibid:188]. 
Mesoamérica ${ }^{34}$ y que considera el desarrollo cultural como consecuencia de la adaptación al medio ambiente; en cambio el concepto de aldea, pertenece al esquema propuesto por Román Piña Chan, el cual propone un desarrollo evolutivo de sociedades igualitarias a sociedades teocráticas para desembocar en sociedades militaristas que se presentan como el momento culminante del desarrollo mesoamericano.

En la narración del libro de texto, no se observa, una construcción gradual del conocimiento que permita a los niños el aprendizaje de los conceptos históricos, así como tampoco de las causas que propician la transformación de las sociedades. Los procesos sociales, parece que se desarrollan solamente por el paso del tiempo. La repetición de los contenidos año tras año, no conlleva un proceso gradual, de menor a mayor complejidad, en la construcción del conocimiento.

Por otro lado, la relatividad de las interpretaciones arqueológicas, producto de la naturaleza de la información y las diferentes formas de explicar los procesos históricos no son transmitidas al lector, al contrario, el libro de texto reafirma la inmutabilidad del conocimiento, lo que a mi parecer es una de las causas del rechazo a aceptar nuevas interpretaciones históricas. Tal pareciera que la versión que se enseña a través del libro de texto es incontrovertible.

La narración en el libro de texto, de la historia prehispánica, se concentra en describir algunos rasgos de cada una de las culturas y en llevar a cabo un ensalzamiento de lo prehispánico. Utilizar adjetivos como "gran cultura mesoamericana", "los asombrosos centros ceremoniales", "elaboraron códices muy bellos”, etcétera, determinan una estructura narrativa que no pretende explicar los procesos históricos. En el libro de texto, se utilizan términos o información proveniente de las investigaciones arqueológicas extraída de su contexto y articulada en un discurso que pretende ser histórico, pero que solamente proporciona una serie de datos, en algunas ocasiones erróneos, que no permiten comprender la historia prehispánica.

Por otro lado, el uso de la imagen con fines didácticos, puede constituir un elemento muy valioso en la enseñanza de la historia, siempre y cuando se evalúe el potencial educativo de la imagen que se inserta en un libro de texto tomando en cuenta que:

- Toda imagen es producto de una época determinada y fue creada de acuerdo a las

$34 \quad$ Sanders, William y Barbara Price. Mesoamérica: The evolution of a civilization, New York, Random House. 1968 
convenciones estéticas de ella.

- La imagen ofrece una interpretación de los hechos que refleja un sistema de creencias, es decir una determinada concepción del mundo ${ }^{35}$

- La imagen es un medio de comunicación y posee una estructura simbólica dirigida a una sociedad que conoce el código transmitido por ella, por tanto, es necesario que un lector de una época diferente aprenda a leer las imágenes.

Pero, como se ha visto, la mayoría de las veces las imágenes no corresponden con el tema tratado, tampoco está en función de proporcionar información que ayude a entender los procesos sociales y tampoco permite conocer la forma en que la arqueología lleva a cabo la reconstrucción histórica.

Por lo que el fracaso en la enseñanza de la historia prehispánica, no es algo que puede achacarse solamente al magisterio y a las deficientes técnicas pedagógicas, sino que tiene su origen en la estructura del libro de texto.

35 Hay que recordar, por ejemplo, la figura de Hernán Cortés representada por Diego Rivera en el mural de Palacio Nacional, donde la imagen del conquistador es la de un hombre feo y deforme por las enfermedades, en contraste con otras imágenes en las que se le representa como un hombre gallardo y viril. 